\title{
DE QUE ADOECEM E MORREM AS MULHERES EM SÃO PAULO*
}

\author{
Luís Eduardo Batista" \\ Margareth A. Santini de Almeida" \\ lone Morita" \\ Anna Volochko" \\ Marina Ferreira Rea"
}

\begin{abstract}
RESUMO: O estudo traça um perfil da morbi-mortalidade feminina no Estado de São Paulo, com enfoque nos problemas reprodutivos. A mortalidade foi estudada nos períodos 1979-81; 1986-88 e 1993-5, a partir do Sistema de Informação em Mortalidade (SIM/DATASUS) e a morbidade de 1996 foi obtida do Sistema de Informações Hospitalares (SIH/DATASUS). O artigo discute as principais causas de internação e morte das mulheres e aponta os desafios para as políticas públicas voltadas a saúde da mulher.
\end{abstract}

PALAVRAS-CHAVE: morbi-mortalidade feminina, problemas reprodutivos, AIDS, doenças cardíacas, doenças respiratórias

* Este artigo é parte do projeto "Estudo Multicêntrico da morbi-mortalidade feminina no Brasil" coordenado pelo Núcleo de Estudos de População - NEPO/UNICAMP e financiado pela Fundação Ford. O estudo foi desenvolvido nos estados do Para, Goiás, Rio Grande do Sul e São Paulo. No estado de São Paulo o estudo foi desenvolvido pelo Instituto de Saúde e pela Faculdade de Medicina de Botucatu - UNESP. E-mail ledu@isaude.sp.gov.br

** Do Instituto de Saúde/CIP/SES, Núcleo de Investigação em Saúde da Mulher e da Criança.

*** Da Faculdade de Medicina de Botucatu - UNESP, Departamento de Saúde Pública. 


\section{INTRODUÇÃO}

Os indicadores de saúde são os instrumentos dos quais a epidemiologia e a demografia utilizam para avaliar a situação de saúde, sendo que o nível de saúde é avaliado pelos processos de mortalidade e morbidade. As estatísticas de mortalidade são alguns dos indicadores utilizados pelos planejadores e administradores de saúde pública para a avaliação da situação de saúde; a definição de prioridades e a alocação de recursos, além da vigilância de problemas específicos de saúde. Os dados de mortalidade também orientam a determinação das prioridades de investigação e a avaliação do impacto de intervenções.

O registro obrigatório das causas de morte levam a criação de um banco de dados, periodicamente divulgado e cuja interpretação fornece um diagnóstico de saúde. Isso faz com que o registro da mortalidade seja um indicador freqüentemente usado em saúde coletiva pelas suas facilidades operacionais - a morte é objetivamente definida e registrada compulsóriamente.

Mas as estatísticas de mortalidade contam uma história muito incompleta sobre a doença e seus determinantes individuais e sociais. Há marcantes diferenças entre homens e mulheres quanto a mortalidade. A mortalidade masculina é sempre maior que a feminina em todas as idades, causas e regiões de modo que a esperança de vida feminina é sempre maior que a masculina (PUFFER, R.R \& GRIFFITH, 1968; VOLOCHKO, 1992). A mortalidade também é maior nos extremos de idade: menores de 1 ano e maiores de 60 anos. $E$ eventualmente em faixas etárias específicas por causas específicas. A mortalidade, além de ser um indicador negativo reflete muito pouco sobre as doenças e seus fatores determinantes, especialmente se não é contemplado o diferencial sócio-econômico. Conseqüêntemente muitas patologias, que não são causas de morte, como transtornos mentais, doenças dermatológicas, osteoarticulares e ocupacionais, com graves efeitos na saúde da população e grande utilização de recursos de saúde ficam excluídas.

Outra vertente importante dos estudos de mortalidade internacional é a discussão e teorização sobre as diferenças sócio econômicas e raciais/étnicas nas taxas de mortalidade. No Brasil poucos estudos incorporam a desigualdade social na mortalidade, entre eles, VICTORA et al, (1988) no estudo de mortalidade de crianças e VOLOCHKO (1992), na pesquisa sobre mortalidade materna em São Paulo. Ambos utilizaram a classificação social adaptada de BRONFMAN \& TUIRÁN, conforme citado por LOMBARDI, et al. (1988, p. 255).

Assim utilizam-se outros indicadores entre os quais os de morbidade. 
A morbidade da população permite avaliar os risco de adoecer a que as pessoas estão submetidas, orientam investigações sobre os determinantes das doenças, apontam para intervenções necessárias. Uma grande vantagem da medida de morbidade é sua sensibilidade a mudanças a curto prazo.

A informação de morbidade decorrente do uso de serviços constitui indicador indireto de morbidade e qualquer tentativa de inferência sobre o perfil de doença na população deve ser muito cautelosa, pois, refletem muito mais a oferta de especialidades e serviços disponíveis do que a morbidade da demanda.

Entretanto, conhecer a freqüência e a distribuição das doenças na população não é tarefa fácil, pois mesmo atualmente, com todo o avanço científico e tecnológico não é simples responder às perguntas: quantas pessoas ficaram ou estão doentes em uma determinada área e espaço de tempo? De quais causas? Como essas causas se distribuem por sexo e idade?" (LEBRÃO, 1997, p.11).

É crescente o número de estudos e pesquisas que procuram compreender 0 encadeamento de alguns dos múltiplos determinantes relacionados à situação da saúde das mulheres, no entanto poucos permitem a elaboração de um diagnóstico abrangente e atualizado da saúde da mulher paulista. Desconhece-se as tendências da morbi-mortalidade feminina, seus diferenciais regionais e suas determinações mais gerais. Falta também um estudo das causas de internação e morte de mulheres nas diferentes fases do ciclo vital, sua evolução no tempo e nas regiões do Estado, que como se sabe, apresentam níveis distintos de desenvolvimento econômico e de atendimento à saúde.

Considerando a necessidade de consolidar, qualificar e contextualizar as informações referentes aos problemas de saúde reprodutiva este artigo têm como objetivo descrever o perfil da morbi-mortalidade feminina no Estado de São Paulo entre 1979-1996, com enfoque nos problemas reprodutivos, contribuindo para o melhor delineamento de políticas públicas para o setor.

A mortalidade foi estudada para os períodos de 1979 a 81; 1986 a 88 e 1993 a 95 utilizando os dados do Sistema de Informação em Mortalidade (SIM/DATASUS). Foram incluídos os óbitos ocorridos em outras Unidades da Federação, para evitar a evasão de óbitos. A morbidade foi obtida a partir de internação nos hospitais pertencentes ao Sistema Único de Saúde em 1996, coligido do Sistema de Informações Hospitalares (SIH/AIH/SUS).

Uma das dificuldades de trabalhar dados de mortalidade a partir do atestado de óbito, deve-se a qualidade da "certificação" médica e as falhas no seu preenchimento. Entre eles, destacamos: 
- imprecisão no diagnóstico, ocasionando cerca de $6 \%$ de causas mal definidas, embora represente uma proporção bastante inferior a de outros estados do Brasil. Verificase, por exemplo, que a região Nordeste apresenta 49\% de causas mal definidas, em 1980 e $36 \%$ em 1990 (SIMÕES, 1997). A marcante diferença reflete as desigualdades regionais de oferta de serviços de saúde e hospitais, bem como sua capacidade diagnóstica;

- mal preenchimento do campo do atestado de óbito referente à existência ou não de assistência médica por ocasião do óbito, dificultando o diagnóstico real dessa situação.

Apesar das limitações apontadas estudos de mortalidade realizados através de dados secundários revelam as condições de vida ao evidenciar mortes evitáveis, precoces e injustificadas (LUIZ, 1997, p. 114), aspectos fundamentais na avaliação da situação de saúde e melhor formulação de políticas públicas.

No que tange a morbidade, ela foi estudada a partir do Sistema de Informações Hospitalares (SIH/DATASUS) para o ano de 1996. A morbidade pode ser ilustrada por um iceberg do qual a ponta que emerge à superfície são as internações hospitalares. A morbidade que demanda cuidados ambulatoriais representa sua porção submersa. A água gelada que rodeia o iceberg é uma transição entre o estado de doença e saúde, uma permanente dinâmica entre estar bem e não estar bem.

Este trabalho se preocupa com a morbidade hospitalar. Isto significa ocupar-se com a menor porção do iceberg, em geral a mais grave ou percebida como mais grave ou diretamente ameaçadora à vida. Eventualmente uma certa proporção da morbidade grave não tem acesso a assistência.

Por outro lado é importante não perdermos de vista que no Estado de São Paulo $55 \%$ da população se utiliza de serviços financiados pelo SUS e que muitas patologias com graves implicações de saúde pública, e especialmente de saúde reprodutiva, não são hospitalizadas, como é o caso da maioria das DSTs. Diferentemente da mortalidade que é um evento único na vida, a morbidade pode ocorrer várias vêzes e uma mesma pessoa pode passar por diversas internações no mesmo hospital, o que implica que as generalizações para a população devem ser feitas com cautela.

Finalmente, no caso específico da fonte de informações usada no presente estudo - as Autorizações de Internações Hospitalares - AlHs, é importante lembrar que o instrumento tem primordialmente função contábil e, portanto, sujeito aos viéses associados à sua natureza. 


\section{RESULTADOS E COMENTÁRIOS}

\section{A MORTALIDADE EM SÃO PAULO}

A taxa de mortalidade feminina de 10 anos e mais no período de $79 / 80 / 81$ foi de 5,51 óbitos em cada mil mulheres, passando a 5,65 por mil em $86 / 87 / 88$ e 5,78 por mil em 93/94/95 (Tabela 1). O comportamento das taxas de mortalidade nos municípios do Estado de São Paulo foram agrupados em três grupos e estão evidenciados no Mapa1.

Pela mortalidade específica pode se verificar que a taxa de mortalidade feminina por idade aumenta conforme se avança nos grupos etários, como era de se esperar, principalmente depois dos 55 anos. Contudo, nos três períodos investigados, as taxas de mortalidade diminuem em todas as idades, com exceção apenas da faixa dos 25 aos 29 anos em que ocorre um leve aumento.

Ao se investigar a mortalidade por idade e causa ${ }^{1}$ as doenças do aparelho circulatório aparecem como primeira causa nos três períodos investigados, embora tenha diminuído de $51,72 \%$ para $43,04 \%$ (Tabelas 2, 3, 4). Em segundo lugar aparecem os neoplasmas, com um comportamento crescente. Constatamos um comportamento crescente, também entre as Doenças do aparelho respiratório e doenças endocrinas nutricionais, metabólicas e transtornos imunitários. No que tange as doenças endócrinas... entre 1986/1994 ocorre uma reviravolta no seu padrão. Enquanto até 1986 essa causa era mais prevalente em mulheres acima dos 55 anos e em geral representada pela Diabetes Melitus, a partir de 1994 ela emerge em mulheres dos 15 aos 54 anos, sendo constituída na maioria pela AIDS.

Quando analisamos a mortalidade por faixas etárias, chama a atenção como primeira causa na população jovem dos 10-14 anos as Causas Externas em torno dos $42 \%$ nos três períodos, seguida dos Neoplasmas, representando $12 \%$. Isto vai se repetir entre os jovens de 15 - 19 anos, onde cresce de 42 a $49 \%$ as causas externas de mortes nos períodos estudados.

Na Região Metropolitana de São Paulo em 1994 (Tabela 5) as doenças do aparelho circulatório, são a principal causa de morte feminina (42,88\%), seguindo-se dos neoplasmas $(18,21 \%)$ e das doenças do aparelho respiratório $(12,70 \%)$. No entanto, nas faixas etárias até 29 anos, as causas externas é que estiveram sempre em primeiro lugar. É a partir dos 30 anos que esse lugar passa a ser das doenças do aparelho circulatório, sendo que nas idades mais avançadas, seu peso percentual é muito mais elevado, chegando a atingir na idade de 65 anos e mais $50,61 \%$ dos óbitos deste grupo.

1 Nos dados apresentados excluiram-se as causas mal definidas, tendo em vista que sua ocorrência não altera a classificação das cinco primeiras causas de morte. 
Considerando-se os óbitos por neoplasmas, verifica-se que é a segunda causa de morte nas faixas 35 a 64 anos, nas demais, varia entre o terceiro e quinto lugar. O câncer de mama é o mais freqüênte, seguido pelo de estômago e o de útero. A letalidade do câncer de colo de útero permanece alta em São Paulo, insunuando diagnóstico e tratamento tardio. Há anos os serviços de saúde colhem citologia oncológica mas o programa apresenta falhas de fluxo e suprimentos além de distorções no recrutamento de mulheres e na referência para tratamento.

Embora as doenças endócrinas, nutricionais, metabólicas e transtornos imunitários (onde se inclui AIDS) ocupem a quarta posição no total geral dos óbitos ocorridos em 1994, com (2891 óbitos 7,94\%) entre as causas, elas estão em segundo lugar em determinadas faixas etárias, aquelas que representam o auge do período reprodutivo, na de 20 a 24 anos (16,05\%); 25 a 29 anos (23,48\%) e na de 30 a 34, com 17,76\%. Segundo Barbosa e Villela, (1996) mesmo com aumento acelerado da AIDS entre mulheres em São Paulo, (desde 1995 a primeira causa de morte na idade fértil) as ações em DST-AIDS são fragmentárias e insuficientes.

\section{A MORBIDADE HOSPITALAR EM SÃO PAULO}

Antes de iniciar a apresentação dos dados de morbidade hospitalar é importante qualificá-los quanto a sua representatividade face ao universo de internações em São Paulo. Estima-se que internações SUS representem cerca de $55 \%$ do total de internações do Estado. Vê-se, desde logo que o contingente de internações fora do sistema SUS é importante. Mais que pagas diretamente pelo cliente, as internações fora do SUS representam o peso de convênios de empresa e pessoais. Suspeita-se que o perfil de internação neste sistema difere do SUS, dando vazão especialmente a cirurgias eletivas, como cirurgias plásticas. Todavia não se dispõe de dados do sistema não SUS para fazer a comparação.

Por outro lado em meados de 1996 todos os hospitais municipais da cidade de São Paulo foram ligados a cooperativas não recebendo os recursos SUS. Assim, parte importante de internações públicas da cidade de São Paulo deixou de ser considerada.

Este quadro torna impossível qualquer generalização sobre situação de saúde ou de assistência hospitalar em São Paulo a partir dos dados do sistema AlH. 


\section{As diferenças capital/interior}

A investigação da morbidade hospitalar mostrou que em 1996 o SUS financiou 2.147.455 internações no Estado de São Paulo, das quais 59,4\% (1.275.894) de mulheres e as demais $(871.561-41,6 \%)$ de homens. Por outro lado, $1.411 .867(65,7 \%)$ internações do Estado de São Paulo ocorreram no Interior enquanto que 735.588 (34,3\%) ocorreram na região Metropolitana. Entre mulheres a proporção de internações no Interior foi $63,8 \%$ enquanto que para homens esta proporção foi $68,6 \%$ (Gráfico 1). Entre as razões de internação, as por Complicações da Gestação, Parto e Puerpério foi $48,8 \%$ na Região Metropolitana e 36,9\% no Interior.

Uma possível interpretação destes dados talvez esteja no fato de as mulheres do Interior preferirem se internar em hospitais privados para parto, com acomodações diferenciadas e principalmente com acesso mais fácil a cesárea. Esta interpretação fundamenta-se na maior taxa de cesáreas no Interior.

Quando analisamos o total de internações no Estado, as mulheres em idade fértil são as maiores ocupantes de leitos hospitalares e pelo menos $41,21 \%$ delas, estão associadas à finalidade reprodutiva e/ou suas complicações.

Em segundo lugar, com 10,2\% aparecem as Doenças do Aparelho Respiratório; 8,8\% para as Doenças do Aparelho Circulatório; $6,2 \%$ de Doenças do Aparelho Gênitourinário e 5,3\% de Doenças do Aparelho Digestivo. Assim a maioria das internações femininas está direta ou indiretamente associada a reprodução e uma proporção menor a doenças relacionadas ao stress (Tabela 6 ).

Para a OMS, gestação e parto só apresentam complicações em 15\% dos casos. Os $85 \%$ restantes são normais. Excluindo 446.940 partos que deveriam ser fisiológicos, as internações femininas se reduzem a 828.954, menos portanto, que o de masculinas, 871.561 em 1996 em São Paulo. Esta inferência é confirmada quando se analisa os dados através de taxas de internação específicas por idade e sexo.

\section{As causas reprodutivas}

No total, ocorreram em 1996, 520.100 internações por Complicações da Gestação, Parto e Puerpério financiadas pelo SUS no Estado de São Paulo. Destas, 46,8\% foram internações para parto normal; $17 \%$ para cesárea sem outra qualificação; $9 \%$ por aborto; $12,4 \%$ por causas obstétricas diretas; $0,31 \%$ por causas obstétricas indiretas e $14,5 \%$ por outras causas. 
Entre 10 e 14 anos ocorreram 5360 internações por gestação no Estado, um pouco mais de $1 \%$. Assim é importante a inclusão desta faixa etária em futuros trabalhos.

O apogeu das internações neste capítulo ocorre dos 20 aos 24 anos, idade que concentra $31,9 \%$ das internações (165.942), seguida pelo grupo de 15 a 19 anos $(23,4 \%)$ e 25 a 29 anos (23,1\%). Assim dos 15 aos 29 anos são internados $78,4 \%$ dos casos. Dos 45 aos 49 só ocorrem 977 internações $(0,19 \%)$.

Entre as causas obstétricas diretas de internação as complicações da gravidez são o grupo prevalente $(80,7 \%)$, seguidas pelas complicações de parto $(16,6 \%)$ e complicações de puerpério $(2,7 \%)$.

Há mais internações neste capítulo no Interior que na Capital. É interessante notar que a proporção de internações por parto normal é 54,7\% na região metropolitana e 40,9\%, no interior, confirmando a maior prevalência de cesáreas no Interior, embora a cesárea sem menção de indicação é apenas marginalmente maior no Interior $17,1 \%$ contra 16,9\% (Tabelas 7,8 e 9).

A proporção de abortos no Interior é ligeiramente inferior, $8 \%$ contra 10,2\% na Capital, embora seja ligeiramente maior em números absolutos. Em 1986 Laurenti (1990) verificou que $12 \%$ das mortes maternas decorriam de complicações do aborto.

Em compensação as internações por causas obstétricas diretas são o dobro no Interior, $15,7 \%$ versus 7,9\% na Capital. A proporção dentro deste ítem também difere. $\mathrm{Na}$ Capital as complicações da gravidez são responsáveis por $67,2 \%$, as do parto por $28,25 \%$ e as do puerpério $4,55 \%$ enquanto no Interior elas são respectivamente $85,8 \% ; 12,2 \%$ e $2 \%$.

Este é um dado importante pois pode indicar que o acesso é mais difícil na Capital, uma vez que $28,25 \%$ são internadas por complicações no parto quando a grande maioria deveria ser internada por complicações na gestação. E também indica que 4,55\% são internadas ou re-internadas no puerpério, um problema de acesso ou complicações do parto que tem alta e depois são re-internadas.

Apesar de teoricamente haver número suficiente de leitos de obstetrícia, em São Paulo, na prática sua localização é inadequada e não há sistema de organização de acesso. Especialmente na área periférica do município de São Paulo há dificuldade de acesso à maternidade, levando as parturientes a peregrinarem por vários hospitais até encontrar vaga (TANAKA, 1995). No distrito de Sapopemba por exemplo, pesquisa mostrou que $25 \%$ das parturientes peregrinam por até 6 hospitais percorrendo até $100 \mathrm{Km}$ (VOLOCHKO et al, 1998). Tentativas de criação de "pool" de leitos tem sido feitos, mas seu resultado ainda não foi analisado. 
Quanto as neoplasias, a principal razão de internação neste capítulo no Estado de São Paulo é por neoplasma benigno do Aparelho Genital feminino, o mais freqüente dos quais é de útero, responsável por $22,1 \%$ das internações por câncer. Neste caso estão incluídos os miomas, que se sabe podem ser um cover para a realização e cobrança da laqueadura pelo SUS. É necessário um estudo específico para investigar este aspecto pois a incidência das laqueaduras e a prevalência real dos miomas se sobrepõe.

É interessante notar que há uma coincidência entre a ordenação das internações e da mortalidade por causas, uma vez que câncer de mama é uma razão de mortalidade mais importante que câncer de útero, mas ainda assim existe um descompasso pois enquanto as mortes por câncer de mama são responsáveis por $17 \%$, as de útero o são por $9,9 \%$ das mortes por câncer em 1994. Assim, verifica-se que, relativamente, as internações para estas causas são insuficientes.

O comentário é ainda mais pertinente no caso do câncer de estômago e de pulmão pois no primeiro caso, enquanto ocorreram em 1996, 889 internações de mulheres por esta razão, em 1994 morreram 3340 pela mesma causa e no segundo, morreram 2729 mulheres mas só foram internadas 717 pelo SUS.

Observa-se que as internações por câncer no Interior ultrapassam as da Àrea Metropolitana em todas as idades a partir dos 20 anos.

Avançando este tipo de questionamento verifica-se que a internação por carcinomas in situ é muito pequena apontando para a inadequação da busca precoce do câncer, com implicações importantes no tratamento e sobrevida das pacientes. Isto evidencia dificuldade de acesso a internações para câncer. Estas provavelmente ocorrem, muitas vezes em estágios avançados da doença, nos quais mesmo um tratamento heróico é incapaz de reverter o processo.

Outro aspecto é a existência de hospitais privados especializados em câncer. A prática privada no caso da oncologia é muito mais atraente para o médico pois é notório que mesmo famílias modestas mobilizam recursos para tratar parentes com esta patologia. Assim parcela importante da população afetada por câncer se trata na rede privada e não constará dos dados de SUS.

Dentre as doenças das Glândulas, da Nutrição e do Metabolismo e Transtornos Imunitários a diabetes é a principal causa de internação deste capítulo, e sua importância aumenta com a idade, passando de $43 \%$ das internações dos 10 aos 14 anos para $64,2 \%$ no grupo de $65 \mathrm{e}+$ mais, grupo em que ocorre a maior proporção das internações. Mas a causa de maior repercursão social é a AIDS (código 279), ela foi responsável por $5,5 \%$ das internações deste grupo totalizando 1412 internações. Também para esta causa as internações no Interior são mais freqüentes em todas as idades. 
Para alguns autores, o crescimento da AIDS entre as mulheres no Brasil, e especialmente em São Paulo no final da década de oitenta, agravou significativamente sua situação de saúde, já precária, especialmente quanto ao exercício da sexualidade e reprodução. (BARBOSA \& LAGO, 1997:1)

\section{CONCLUSÕES}

A participação da mortalidade de mulheres de 10 anos e mais tem se mantido em torno dos $39 \%$ do total de óbitos do Estado de São Paulo.

A taxa de mortalidade feminina está abaixo de 6 óbitos em cada 1000 mulheres, havendo municípios do Estado em que esta taxa é bem mais baixa.

A taxa de mortalidade feminina tem tendência decrescente, exceto nos grupos de 15 a 19 anos (permanece estacionária); 20-24 anos (aumenta um pouco) e 25 a 29 (aumenta consideravelmente). O mais significativo é que o estacionamento ou reversão da tendência na mortalidade se deve à emergência da AIDS com grande impacto na idade reprodutiva. Constatamos que os óbitos por AIDS migraram da faixa etária 30-34 anos para a de 25-29 anos.

Entre as causas de óbitos, destacam-se: as doenças do coração, como a principal causa de morte entre as mulheres. A segunda causa são as doenças cerebro-vasculares e a terceira outras formas de doença do coração.

Nos anos mais recentes estudados (93/95) as causas externas são as primeiras causas de morte de todas as jovens até 34 anos. Os acidentes de transito representam a primeira causa de morte por Causas Externas, com um número absoluto crescente. Em segundo lugar vem as Outras Causas Violentas.

Em 1994 a primeira causa de morte para mulheres de 10-34 anos foram as causas externas e a segunda a AIDS, exceto no grupo de 10-14 anos. Já para as mulheres de 35 a 64 anos a primeira causa de morte foram as doenças do aparelho circulatório e a segunda as neoplasias.

O câncer de mama é a principal causa de morte entre os neoplasmas, seguido pelo estômago. Os números absolutos tem aumentado mas o tratamento dos dados de mortalidade não nos permite estabelecer conclusões sobre a tendência do risco. 
O número absoluto de mortes maternas tem se reduzido, e alterado seu perfil. Apresenta uma redução o aborto e a hipertensão associada à gestação. Há um aumento das outras causas.

As Autorizações por Internações Hospitalares-AlHs, induzem a determinados diagnósticos, assim a morbidade não reflete a saúde mas a assistência prestada aos usuários do SUS. Em São Paulo, eles representam pouco mais da metade da população. Mesmo assim cabe ressaltar que a AlH possibilitou traçar perfís regionais sobre saúde reprodutiva feminina, subsídios para a avaliação em saúde e levantar hipóteses para trabalhos futuros.

O número absoluto de internações masculinas é menor que o feminino. Entretanto, eliminando as internações por gestação, parto e puerpério as taxas de internação masculina excedem a feminina em quase todas as idades e por todas as causas.

As taxas de internação no interior são maiores que as da Região Metropolitana.

As principais razões de internação são as decorrentes de gestação, parto e puerpério, seguidas por doenças respiratórias e circulatórias.

Com relação a qualidade dos bancos de dados verificam-se poucas inconsistências, e com as devidas considerações, é um ótimo instrumento para o estudo da morbi-mortalidade. 


\section{REFERÊNCIAS BIBLIOGRÁFICAS}

AYRES, J.R.de C. Epidemiologia e emancipação. Hucitec:São Paulo, Abrasco: Rio de Janeiro, 1995.

BARBOSA, R.M. e Lago, TG. AIDS e direitos reprodutivos: para além da transmissão vertical. In: PARKER, R. (orgs.) Políticas, Instituições e AIDS. Enfrentando a epidemia no Brasil. Rio de Janeiro: Zahar/ABIA. 1997. p 163-75.

BARBOSA, R.M. , Villela, W.V. A Trajetória Feminina da AIDS. In:PARKER, R \& GALVÃO, J.(orgs.) Quebrando o silêncio. Mulheres e AIDS no Brasil. ABIA, IMS-UERJ, Relume Dumará. p. 17-32.1996.

BARBOSA, R.M. Feminismo e AIDS. In: Parker, R e Galvão, J. Quebrando o silêncio. Mulheres e AIDS no Brasil. Rio de Janeiro: Relume Dumará: ABIA, IMS-UERJ, 1996. p.153-68.

LOMBARDI, C. et al. Operacionalização do conceito de classe social em estudos epidemiológicos. Rev. Saúde Pública,1998; 22(4): 253-65, 1988.

BEMFAM (Sociedade Civil de Bem Estar Familiar no Brasil). Brasil: Pesquisa Nacional sobre Demografia e Saúde. Rio de Janeiro: Macro Internacional, 1997.

BEMFAM, PNAD/96 In: A Infância Brasileira nos Anos 90. UNICEF. Brasília, novembro de 1998.

BONADIO, IC. Ser tratada como gente: a vivência de mulheres atendidas no pré-natal de uma instituição filantrópica. São Paulo, 1996. [Tese de doutorado. Escola de Enfermagem da Universidade de São Paulo].

CERQUEIRA, C.A., PAES, N.A. Mortalidade por doenças crônico-degenerativas e relações com indicadores sócio-econômicos no Brasil. In: ENCONTRO NACIONAL DE ESTUDOS POPULACIONAIS, XI, 1998, Caxambú. ANAIS... Caxambú: ABEP, 1998, p. 1975-92.

CHOR, D.; DUCHIADE, M.P., JOURDAN, A.M. Diferencial de mortalidade em homens e mulheres em localidade da Região Sudeste, Brasil, 1960, 1970 e 1980. Rev. Saúde Pública 1992; 26(4): 246-55.

CUNHA, E.M.G.P. Os neoplasmas malignos na população feminina brasileira. In: 
ENCONTRO NACIONAL DE ESTUDOS POPULACIONAIS, XI, 1998, Caxambú. ANAIS ... Caxambú: ABEP, 1998, p. 1929-46.

DOMINGUES, R.M.S.M. Sífilis congênita: uma doença secular desafiando o terceiro milênio. In: Saúde em Foco. Informe epidemiológico em Saúde Coletiva. Secretaria Municipal de Saúde do Rio de Janeiro. 1998; Ano III, 17. p 30-33.

KALCKMANN, A. S. Dinâmica de uso do diafragma como método contraceptivo entre usuárias de serviços públicos de saúde. São Paulo, 1995. [Dissertação de Mestrado em Ciências em Epidemiologia - Escola Paulista de Medicina, Universidade Federal de São Paulo].

LAGO, T. G. Saúde, vulnerabilidade e prevenção. Mulher em dados. FSEADE, 3., 1997, p.1.

LAURENTI, R. et al. Mortalidade de mulheres em idade fértil no Município de São Paulo (Brasil), 1986. II Mortes por causas maternas. Rev. Saúde Pública, 24:1468-71, 1990.

LEBRÃO, M.L. Estudos de morbidade. São Paulo:EDUSP; 1997.

LUIZ, O. C. Perspectivas da avaliação de situação de saúde: uma apreciação crítica. São Paulo, 1997. [Dissertação Mestrado em Medicina Preventiva - Faculdade de Medicina, Universidade de São Paulo].

NEDEL, F.B; ROCHA, M. \& PEREIRA, J. Anos de vida perdidos por mortalidade: um dos componentes da carga de doenças. Rev. Saúde Pública, 33(5):461-69, 1999.

PEREIRA, M. G. Epidemiologia: teoria e prática. Rio de Janeiro:Guanabara Koogan, 1995.

PLAUT, E. \& ROBERTS, E. Preventable mortality: indicator or target? applications in developing countries. WId Hlth statist. quart., 42:4-15, 1998.

PUFFER, R. R \& GRIFFITH, G. W. Caracteristicas de la mortalidad urbana. Organization Panamericana de Salud, Washington, 1968.

SANTO, A.H. Causas múltiplas de morte: formas de apresentação e métodos de análise. São Paulo, 1988. [Tese de Doutorado - Faculdade de Saúde Pública, Universidade de São Paulo].

TADDEUS, S. \& MAINE, D. Too far to walk. Soc. Science Medicine, 1997. 
TANAKA, ACA. Maternidade. Um dilema entre nascimento e parto. São Paulo:Hucitec Rio de Janeiro:Abrasco, 1995.

VICTORA, C.G, BARROS, F. C e VAUGHAN, J.P. Epidemiologia da desigualdade: um estudo longitudinal de 6.000 crianças brasileiras. São Paulo:Hucitec, 1988.

VOLOCHKO, A. Mortalidade de mulheres: mortalidade materna. São Paulo, 1992. [Dissertação de Mestrado em Saúde Pública - Faculdade de Saúde Pública, Universidade de São Paulo].

VOLOCHKO, A; Escuder, MML e Hayes, E. Peregrinação em busca do local de parto. Sapopemba, São Paulo, 1997. V Congresso da Abrasco, Águas de Lindóia, 25-29 Agosto de 1998. ANAIS... V Congresso da Abrasco, 1998.

VOLOCHKO, A; Marchi, MLS e Hayes, E. Construção social do sistema de reserva de vaga obstétrica. Acesso e qualidade do serviço obstétrico. Perspectiva da cliente. Núcleo de Investigação de Saúde da Mulher e Criança. Instituto de Saúde, São Paulo, 1998a. (Projeto de pesquisa) mimeo.

WHITE, K. L.; Williams T. F \& GREENBERG, BG. The ecology of medical care. New England J Med, 265:885-92, 1961.

WHO (1991). Maternal Mortality: A Global Factbook. Geneva. WHO/MCH/MSM/91.3. p. 295-304.

WHO. Proceedings of the Meeting on Socioeconomic Determinants and Consequences of Mortality. Mexico City. 19-25 June, 1979. WHO, New York, 1979.

\section{Http://www.seade.gov.br/cgi-bin/titabp/shtab?dem/ANU94/dem94004-COLTAB}

\section{Http://www.saude.gov.br/inform/indica/indica2.htm}

Agradecemos as contribuições de: Ruy Laurenti, Maria Lúcia Lebrão, Luis Patrício Ortiz, Deise Oshiro, Eliete Cândida de Lima Cortez; Francisco Trocolli; Jayme laperuta Filho; Olinda do Carmo Luiz; Sara Romera Sorrentino; Suzana Kalckmann; Tânia Giácomo do Lago e Wilza Vieira Villela. 


\section{THE FEMALE MORBIDITY AND MORTALITY IN THE STATE OF SÃO PAULO}

SUMMARY: This study aims at outlining a female morbidity and mortality profile in the State of São Paulo, focusing on the reproductive problems and contributing to a better formulation of public policies for the sector. Mortality data were collected from the Mortality Information System (SIM/DATASUS), in the periods 1979-81; 1986-88 and 1993-95, and morbidity data were gathered from the Hospital Information System (SIH) DATASUS) in 1996. It was observed that the female mortality rate has a decreasing trend; stagnation or reversion of the trend in mortality is due to emergence of AIDS, with a major impact on the reproductive period. Cardiac and cerebrovascular diseases stand out as causes of death. As to morbidity, the main reasons for hospitalization are related to pregnancy, labor and puerperium. followed by respiratory and circulatory diseases. Hospitalization rates in the countryside are higher than in the Metropolitan Area.

KEY WORDS: female morbidity and mortality, reproductive problems, AIDS, cardiac diseases, respiratory diseases 
을

『

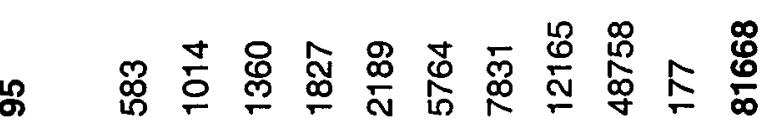

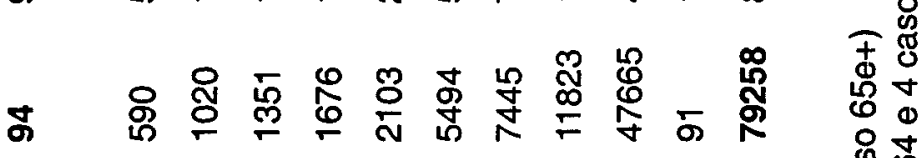

舟車

\%

मे

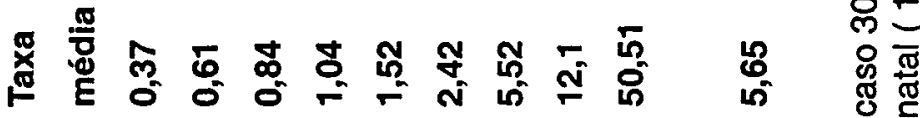

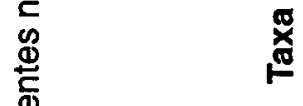

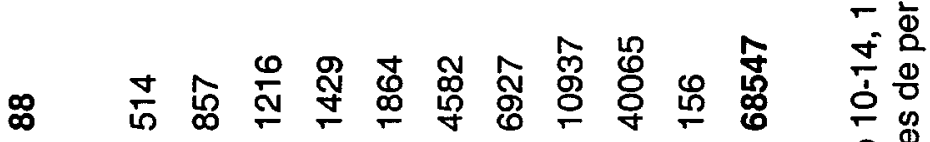

$\frac{\infty}{\pi}$

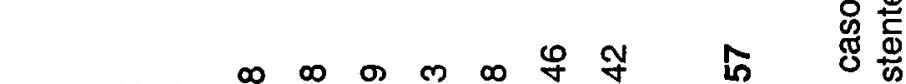

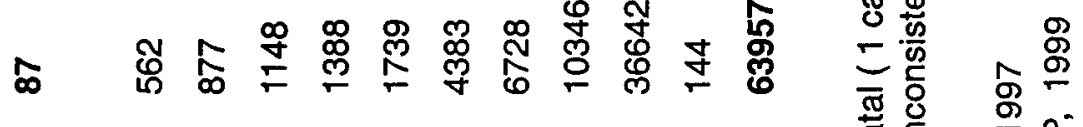

0

ญे

\%ั

.

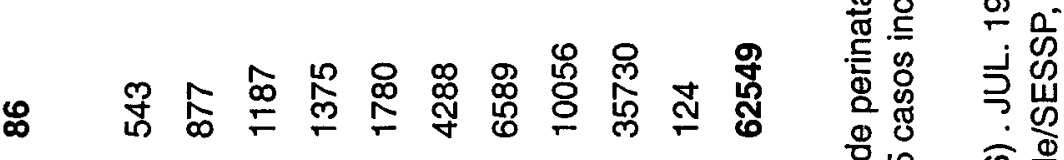

ए

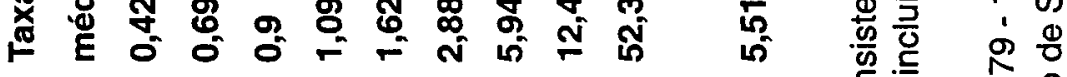

은

응

\&

또ํ 논

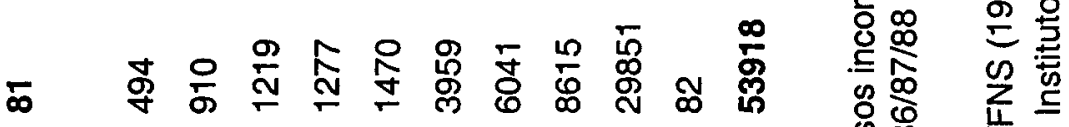

Е

ช్

$\Phi$

묭

!

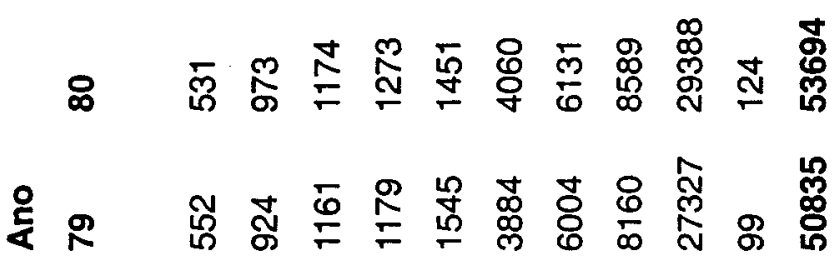

号

픈

कू

鸟 


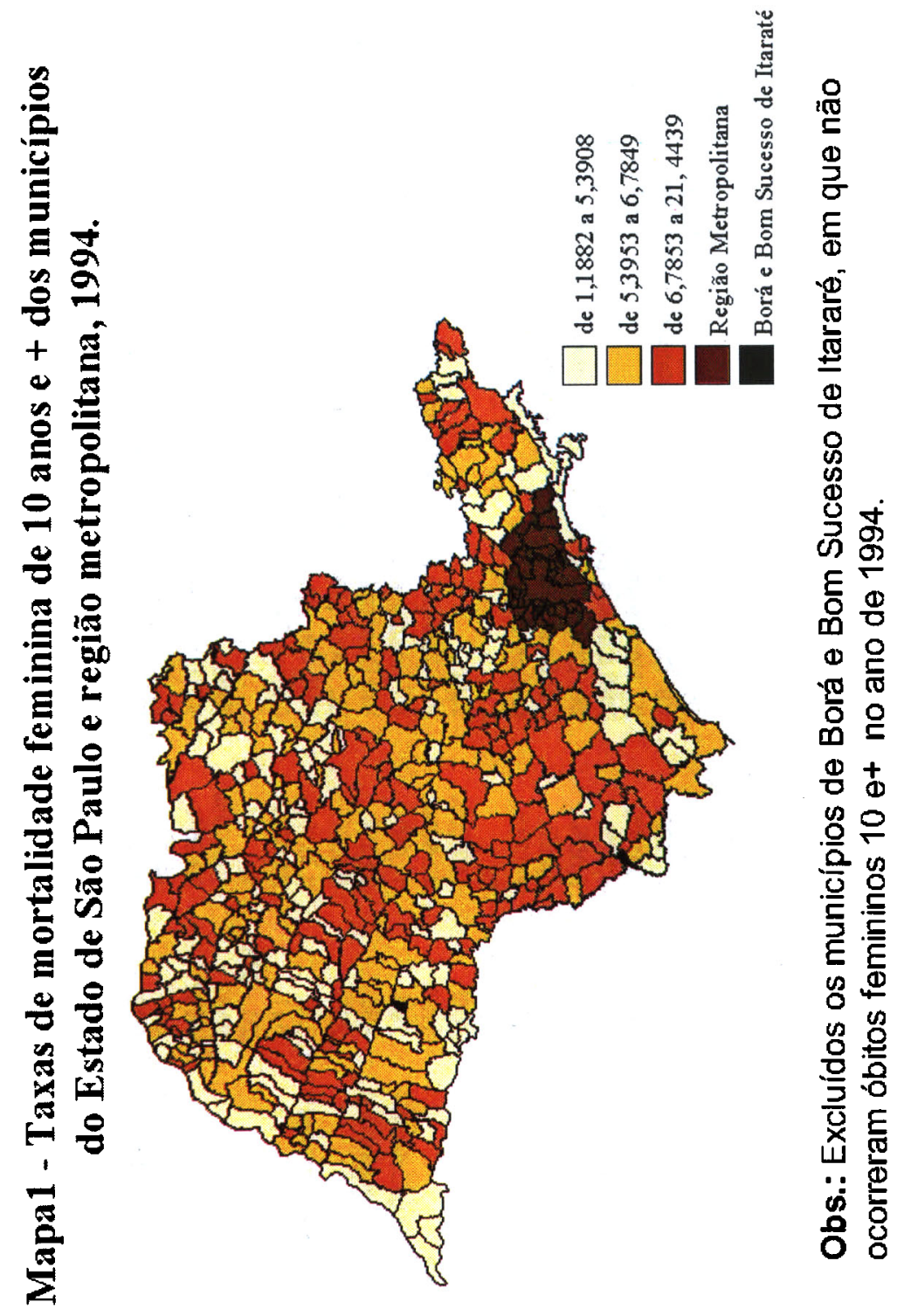




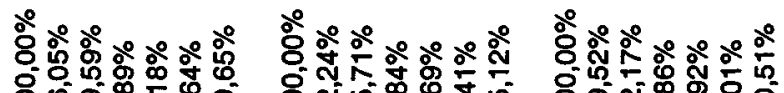
。

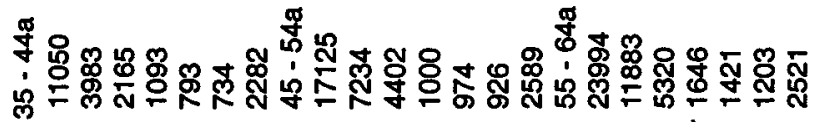
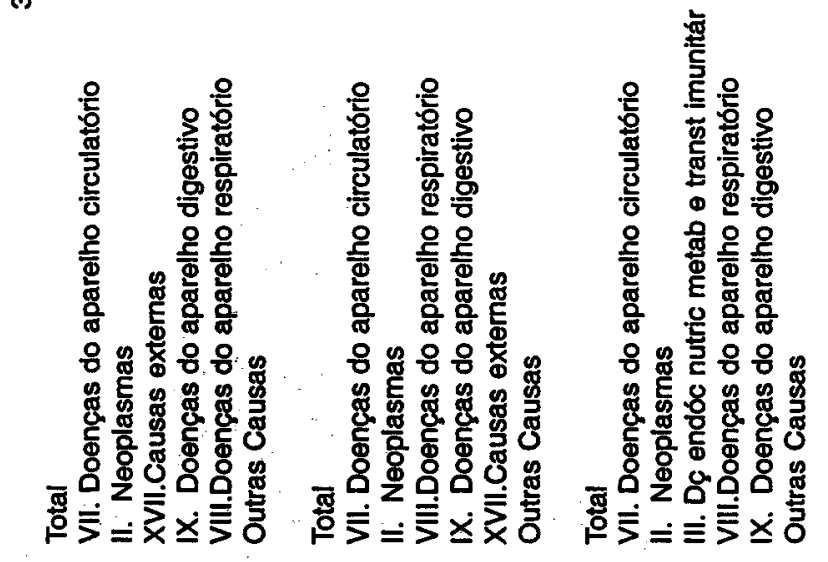

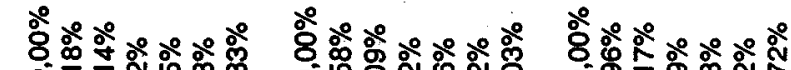 ๙}

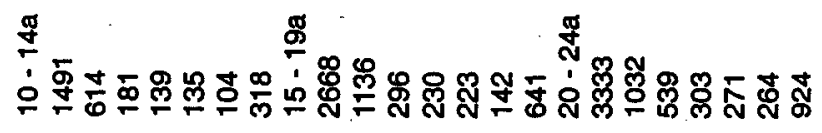
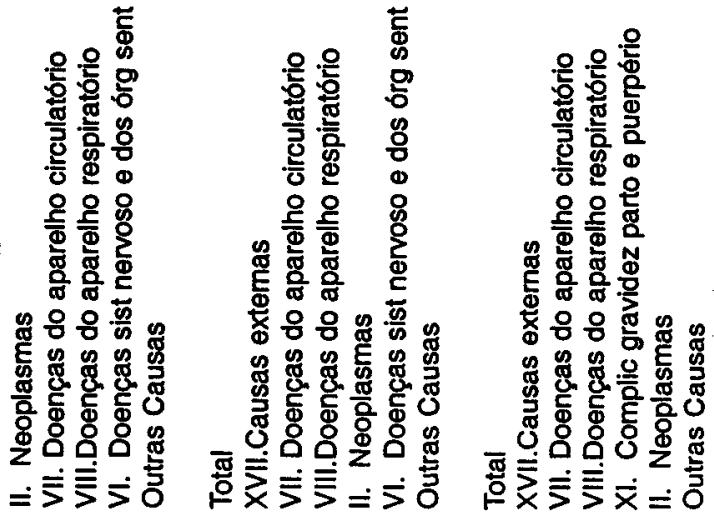


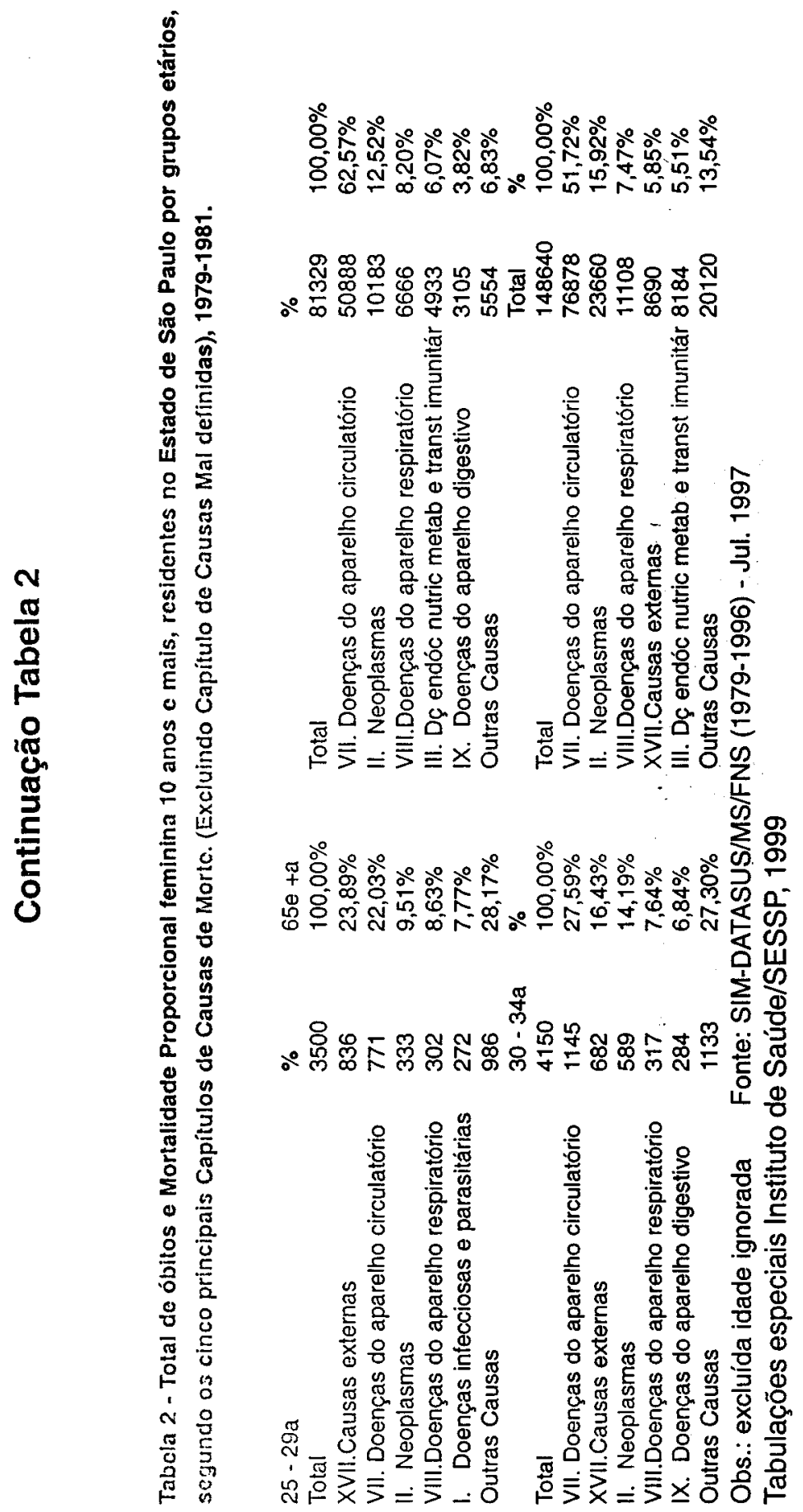




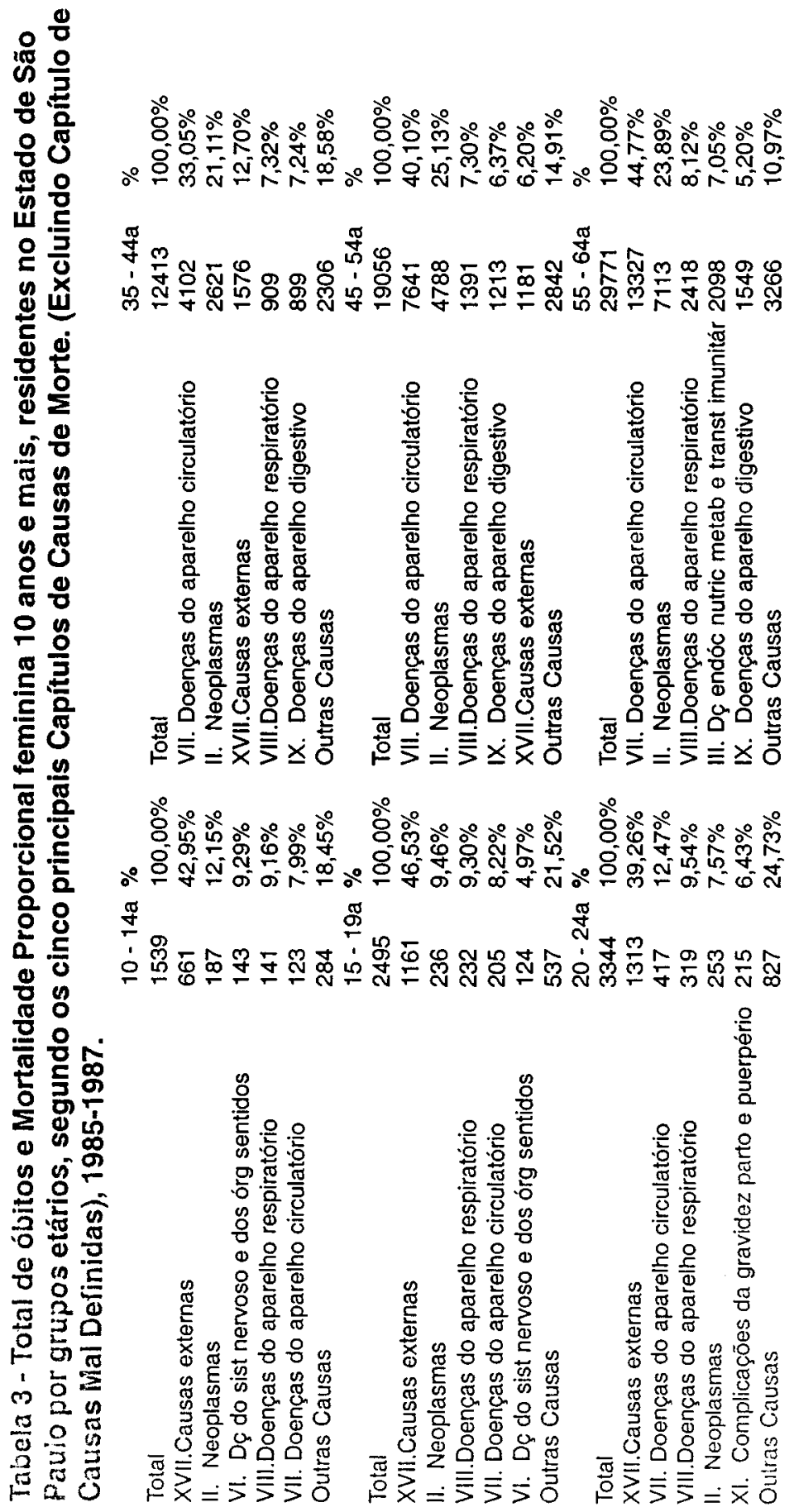




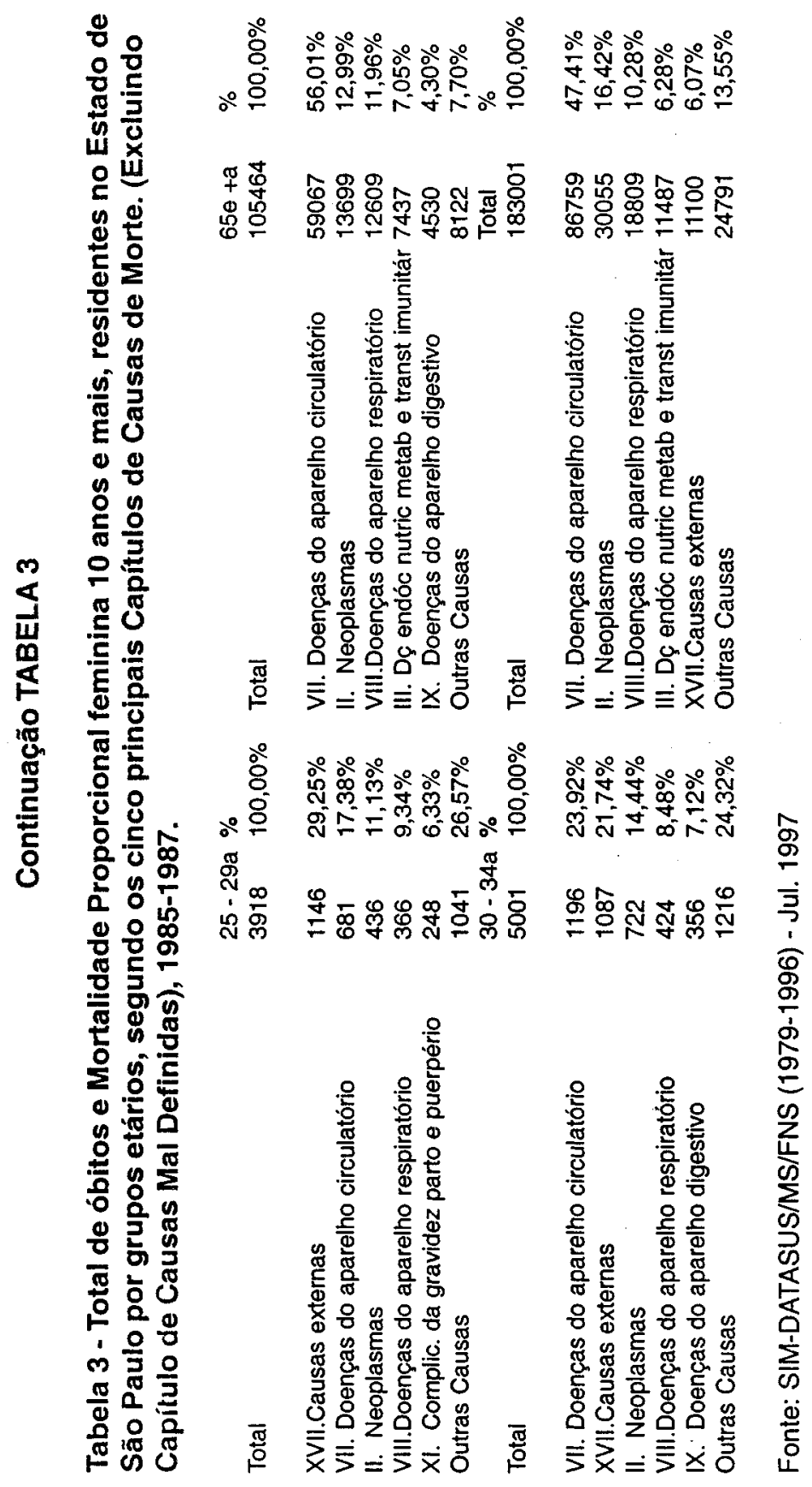




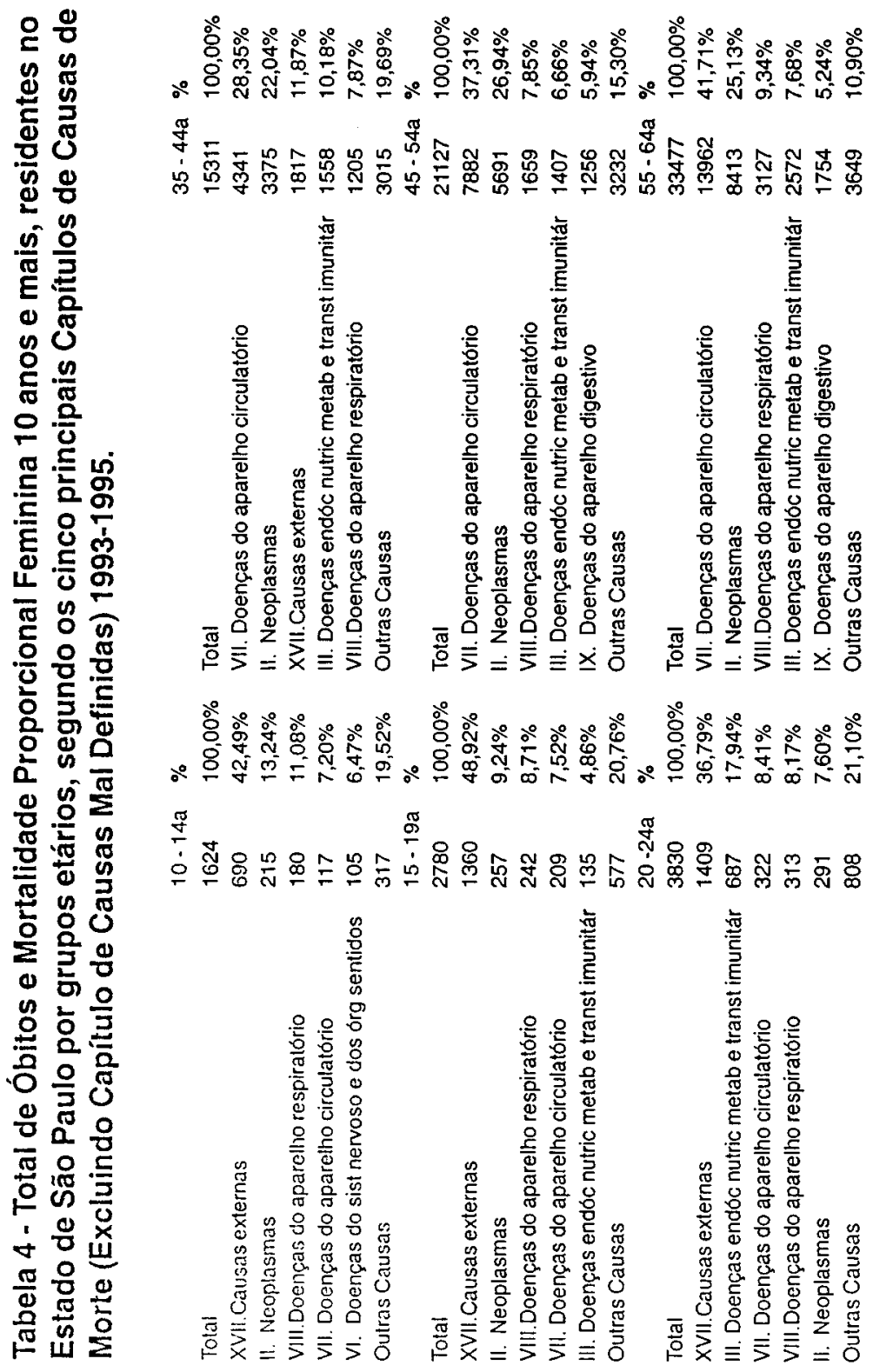




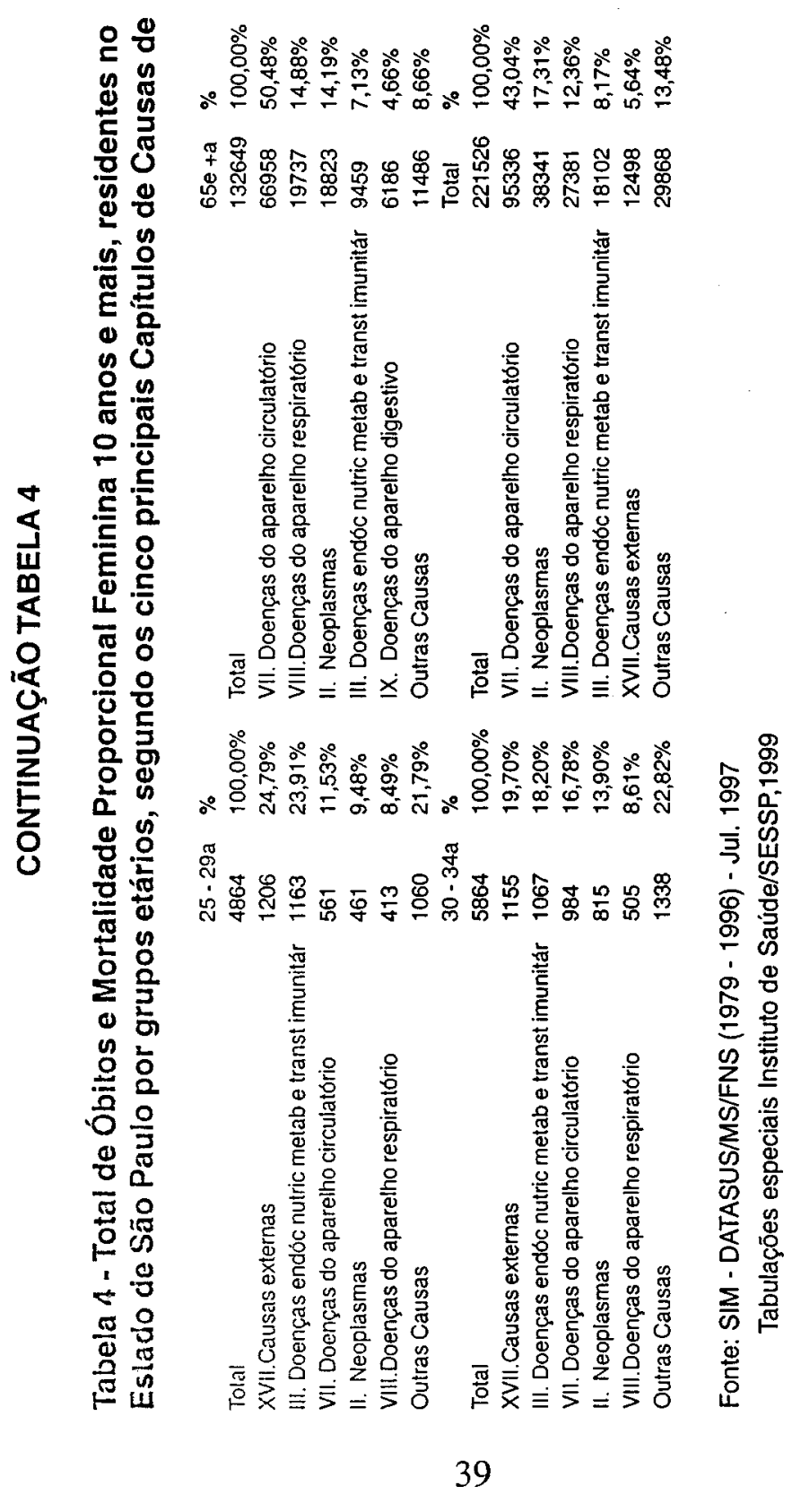




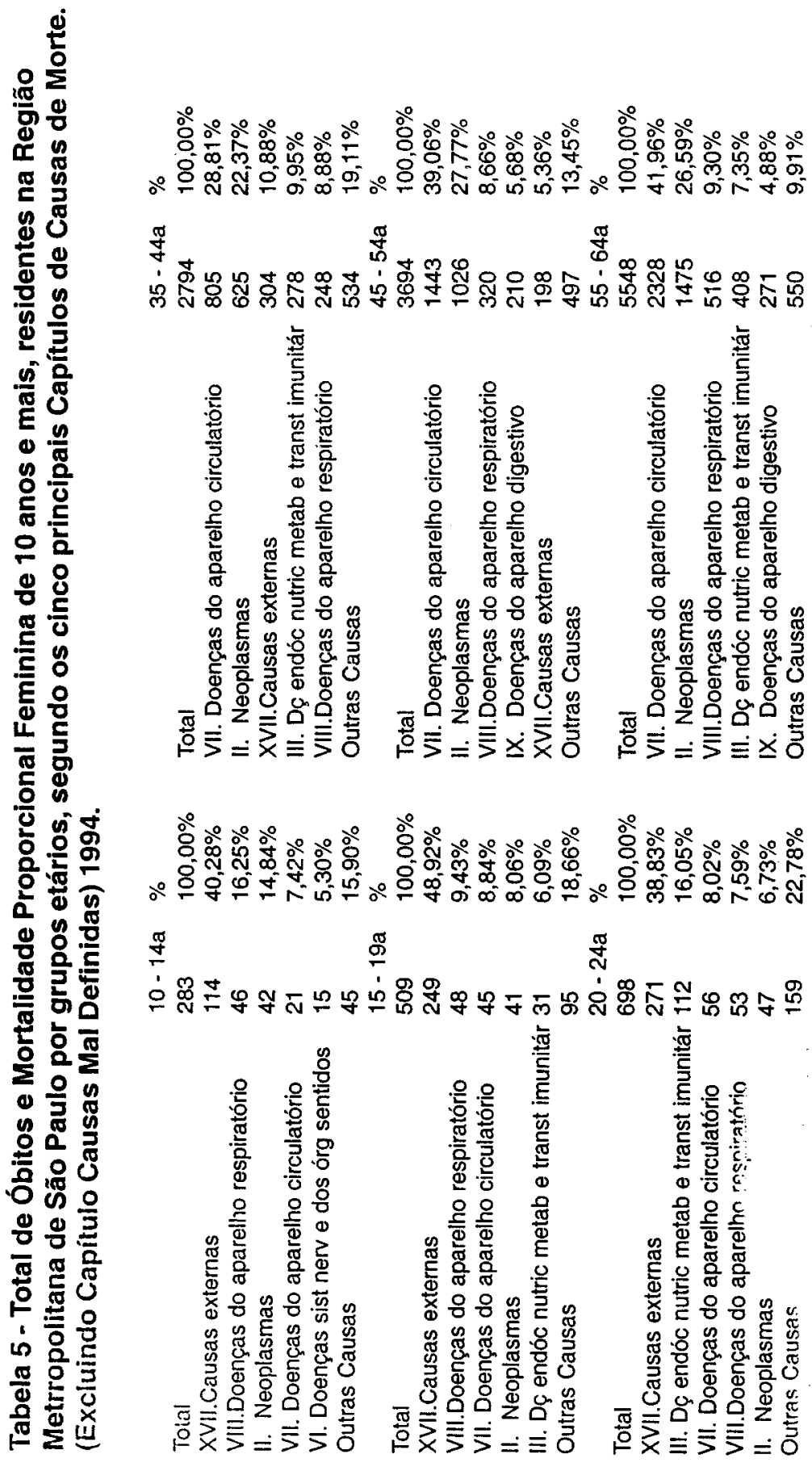




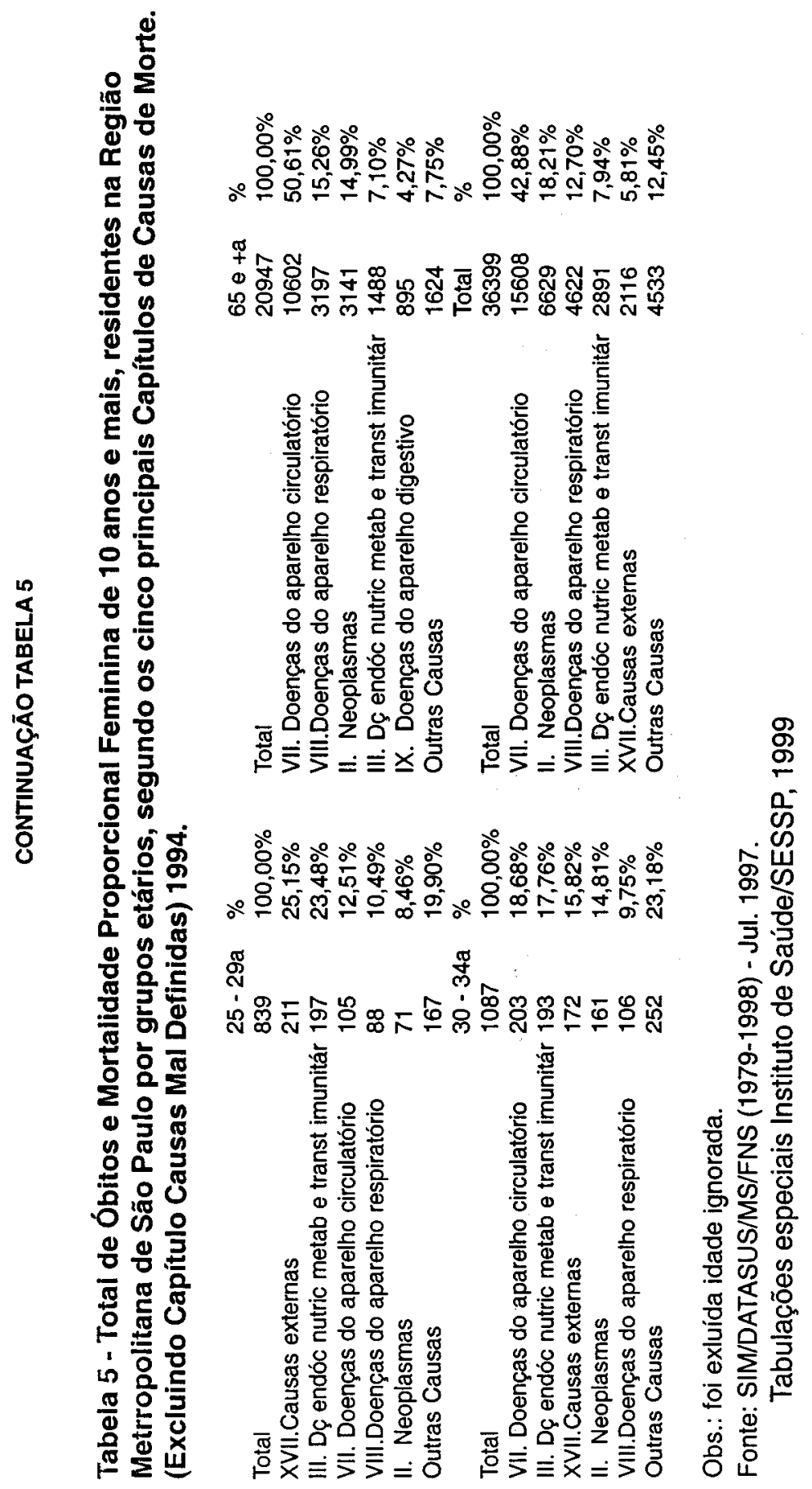




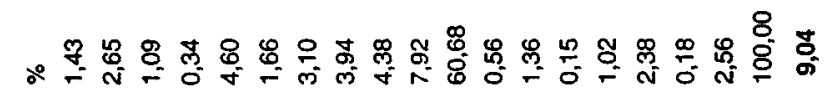

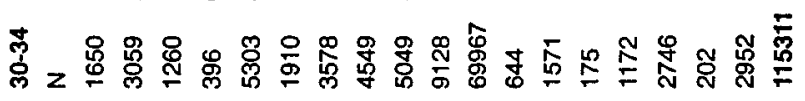

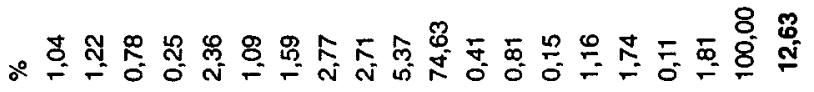

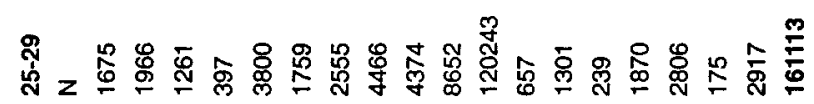

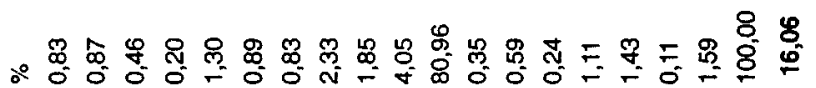

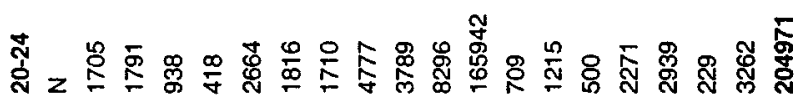

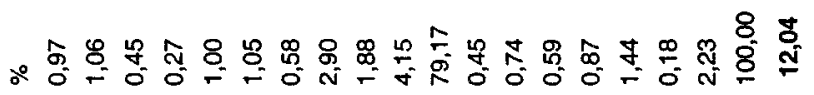

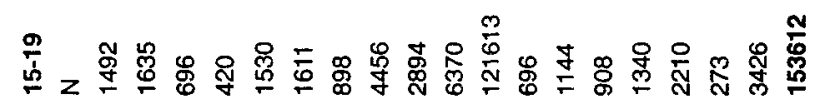

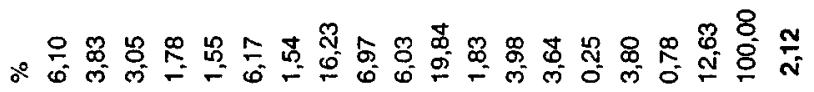

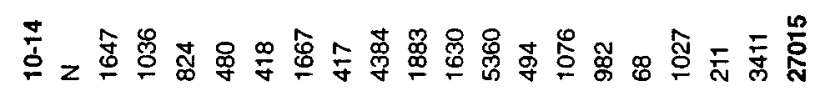

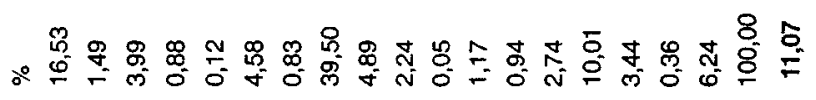

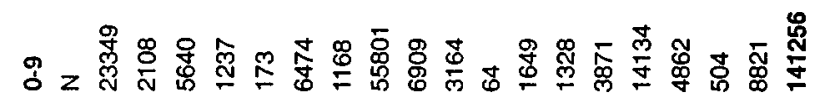

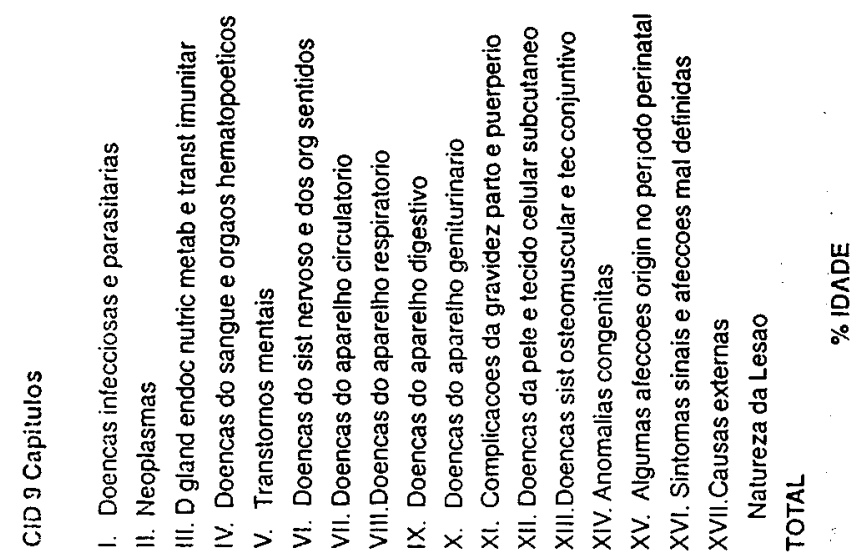




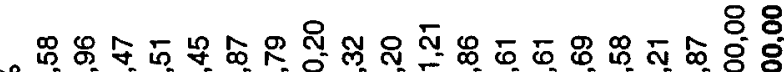
० ल

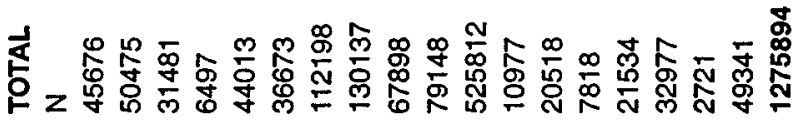

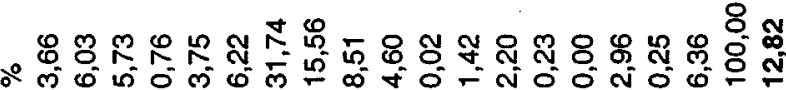

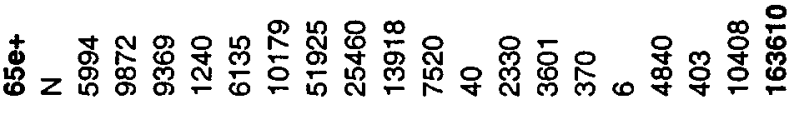

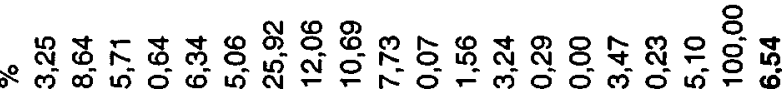

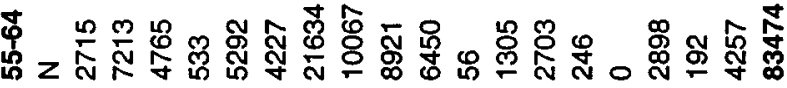

舟至

ㅇำ

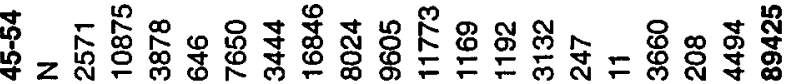

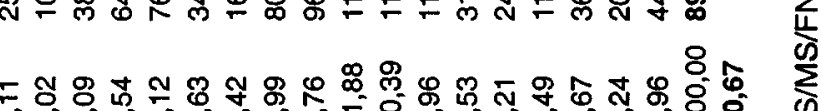

๙ त क N

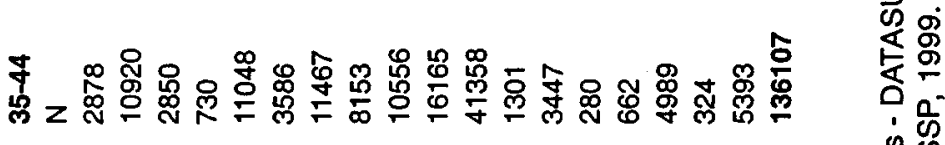

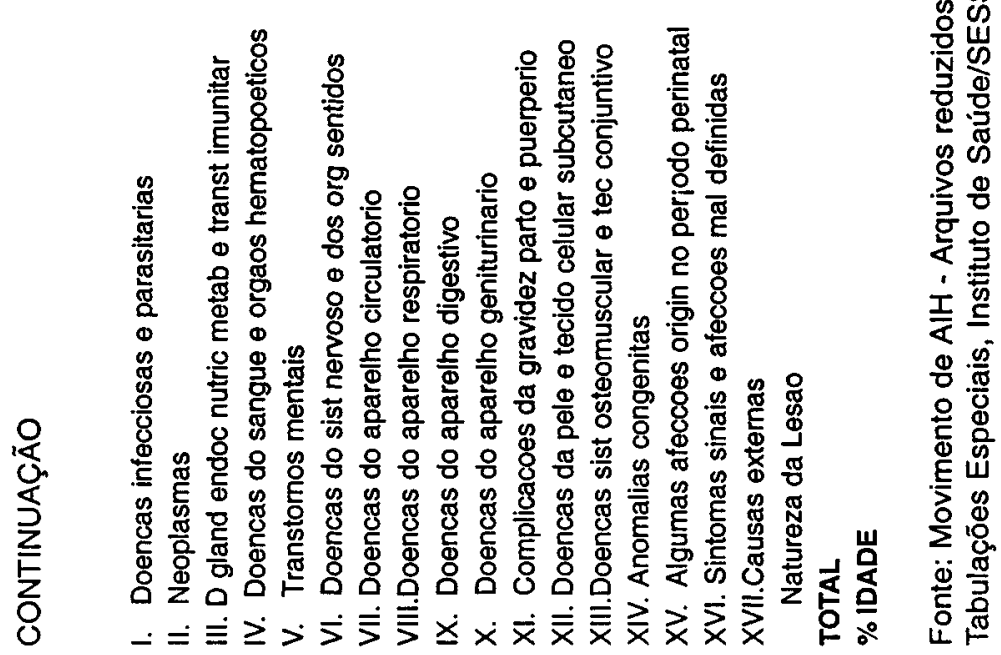




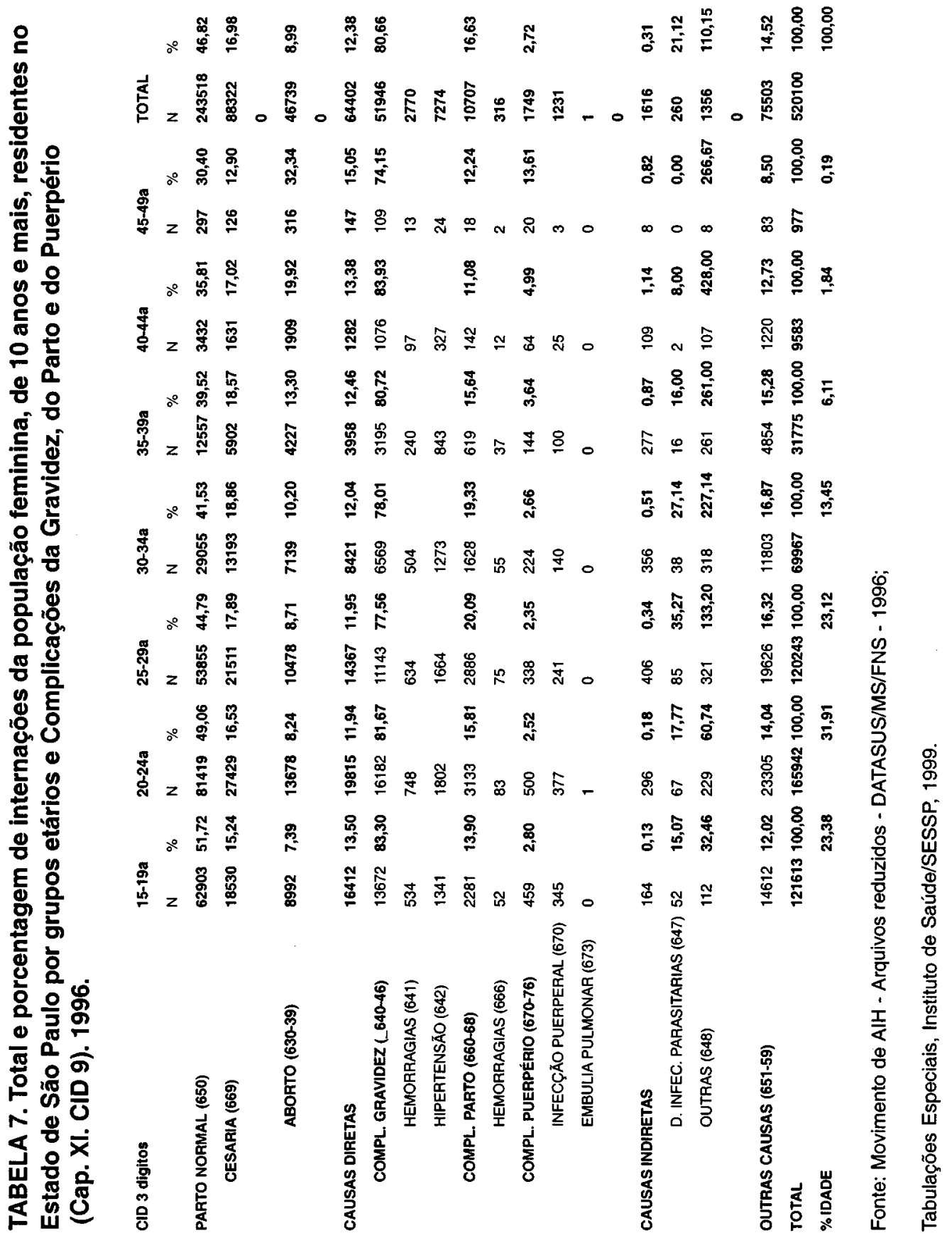




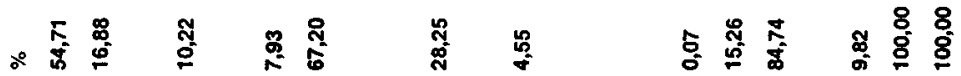

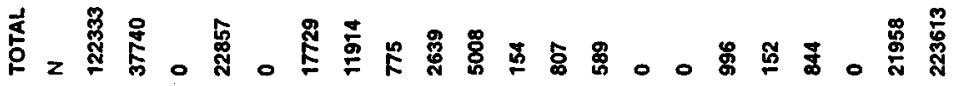

은 은

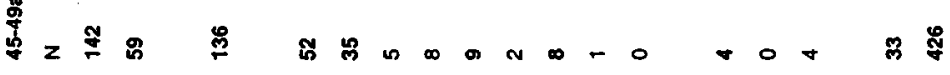

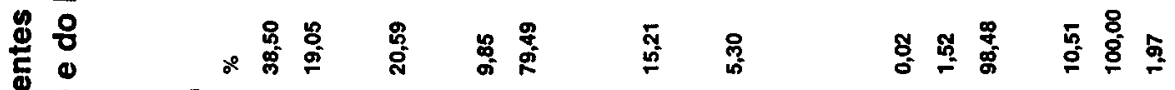

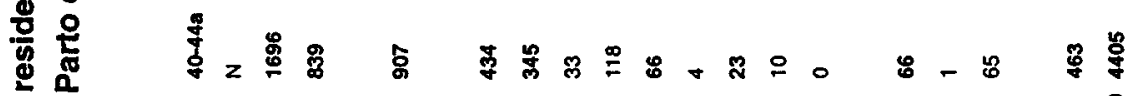

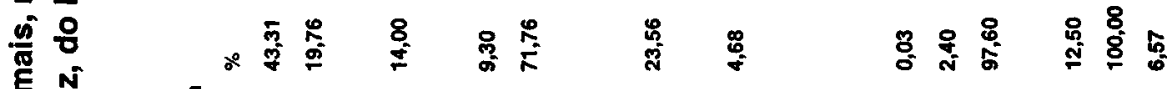

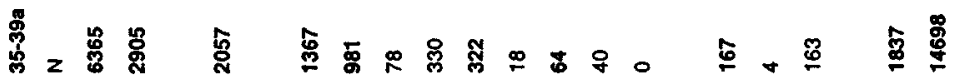

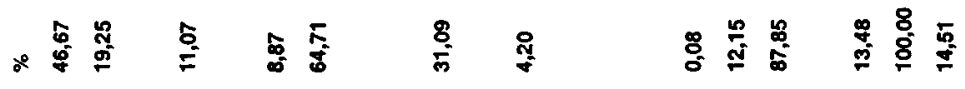

으

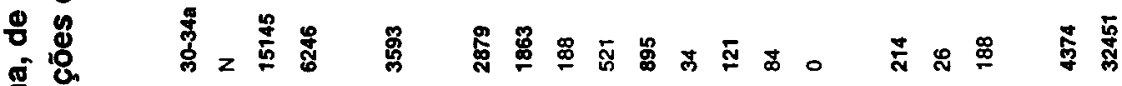

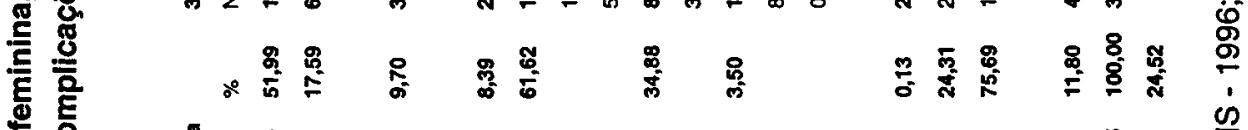

退

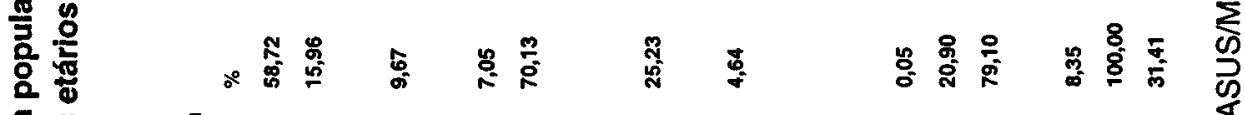

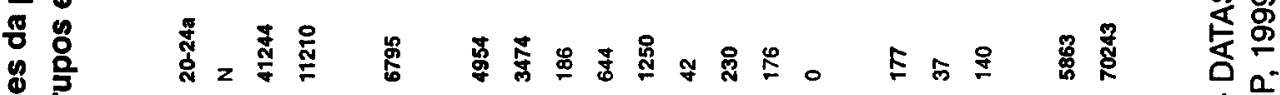

忌家

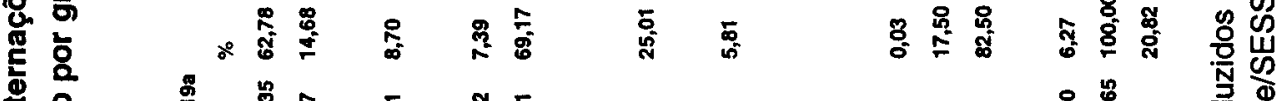

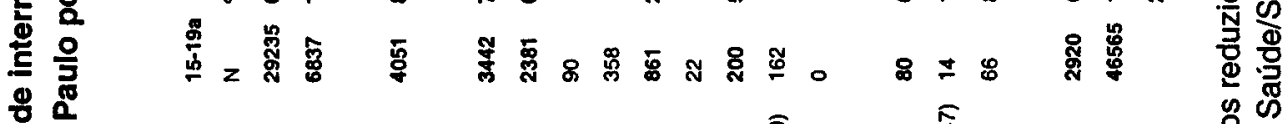

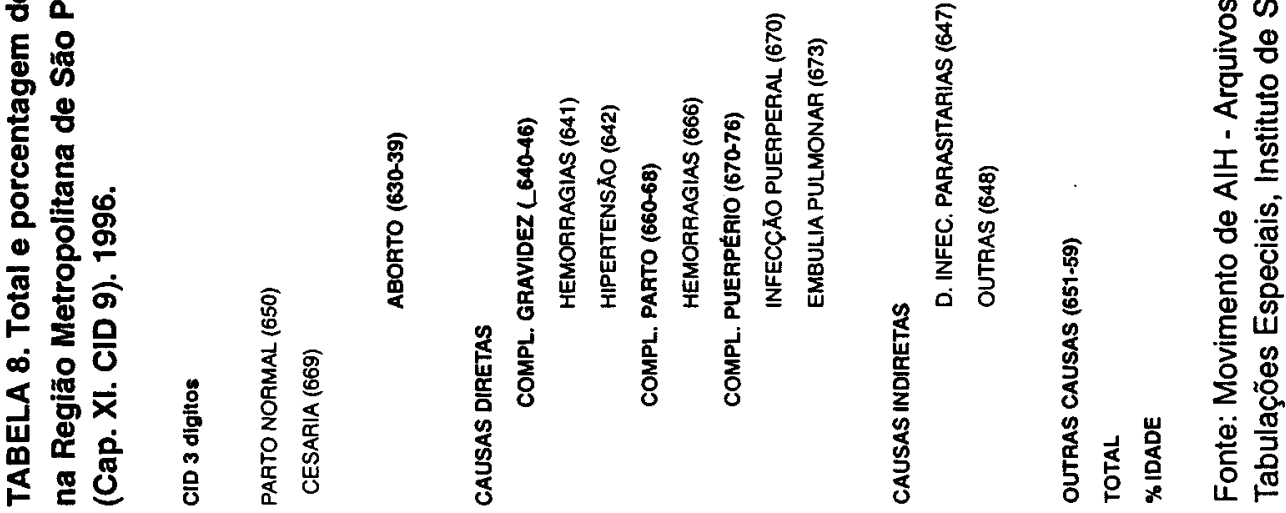


$\frac{g}{\frac{9}{9}}$

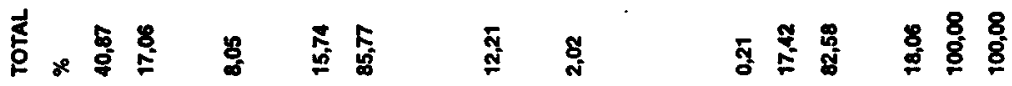

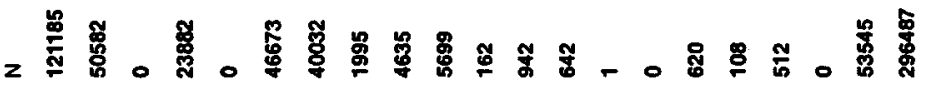

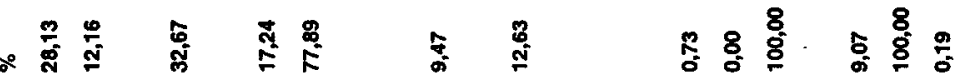

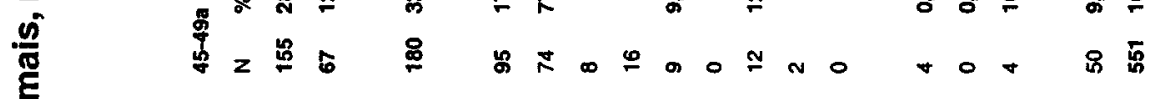

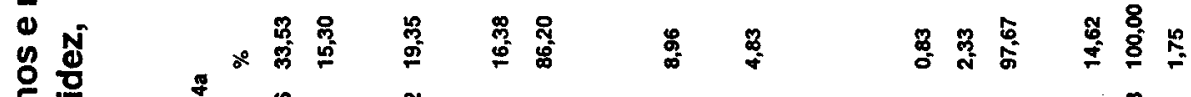

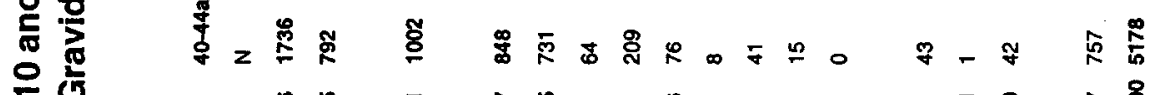

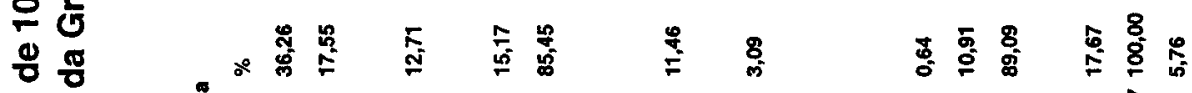

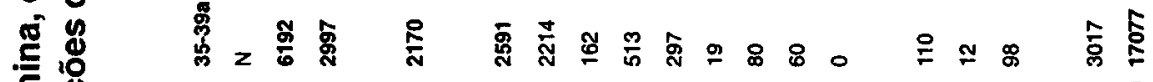
点过 एँ 苟 हुำ

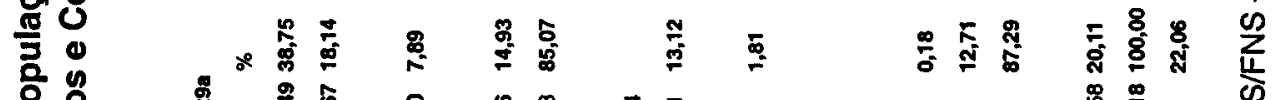

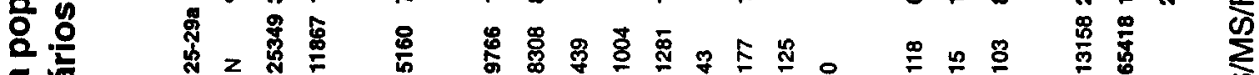

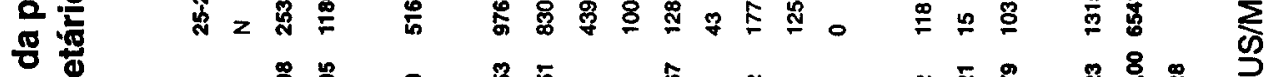

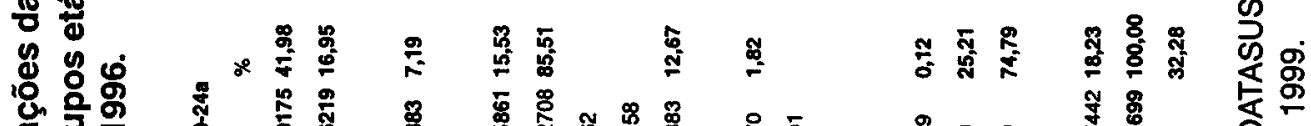

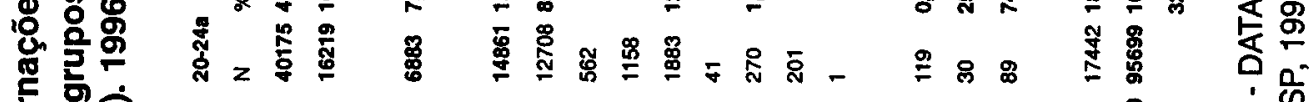

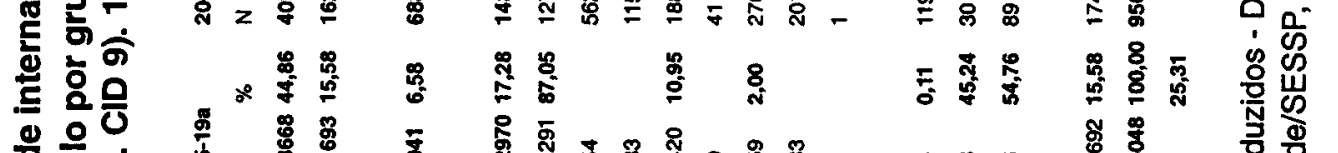

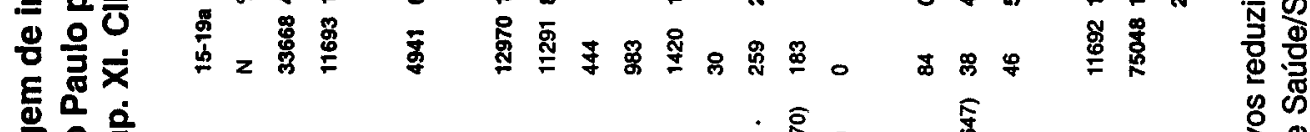
哥品 댕요 응윰응 둥 으 응 음 कं ㅎํ

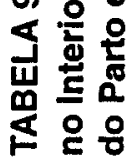
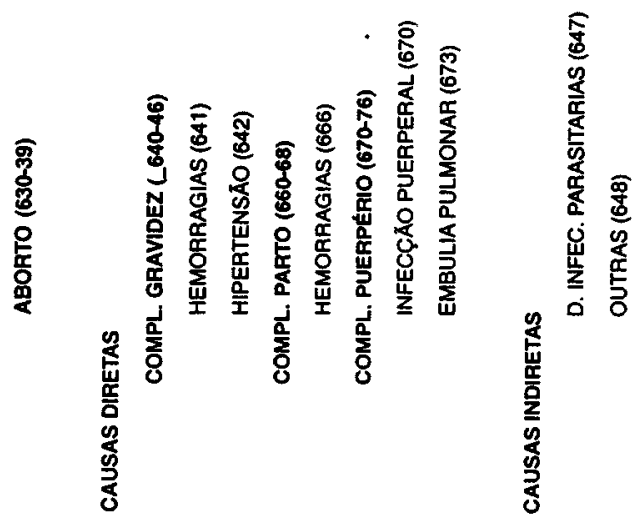


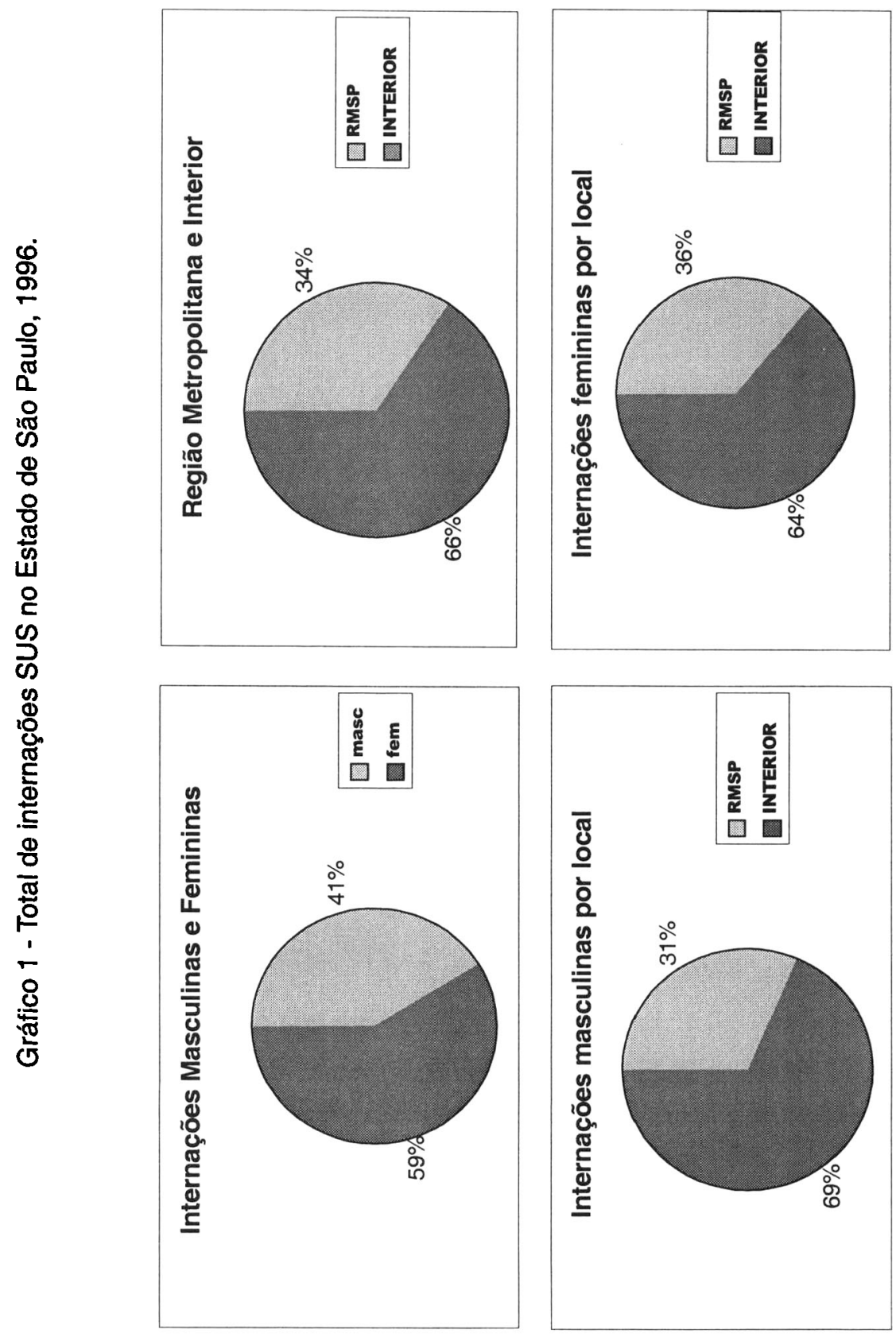

